Journal of Current and Advance Medical Research

January 2019, Vol. 6, No. 1, pp. 47-52

http://www.banglajol.info/index.php/JCAMR

ISSN (Print) 2313-447X

ISSN (Online) 2413-323X

NLM Catalog ID 101673828

DOI: https://doi.org/10.3329/jcamr.v6i1.40785

ORIGINAL ARTICLE

OPEN $\bigcirc$ ACCESS

\title{
Maternal and Socio-Demographic Factors Associated with Birth Weight of Newborns Delivered at a Teaching Hospital of Dhaka City
}

\author{
Sadia Afrin ${ }^{1}$, Anisur Rahman ${ }^{2}$, Afsar Ahammed $^{3}$, Shaila Afrin ${ }^{4}$, Md. Khalequzzaman Sarker ${ }^{5}$, \\ Ahmed Hossain ${ }^{6}$
}

${ }^{1}$ MD Resident, Department of Physiology, Bangabandhu Sheikh Mujib Medical University, Dhaka, Bangladesh; ${ }^{2}$ Assistant Professor, Department of Gastroenterology, Sher-E- Bangla Medical College, Barishal, Bangladesh; ${ }^{3}$ Lecturer, Department of Physiotherapy, NITOR, Dhaka, Bangladesh; ${ }^{4}$ Medical Officer, Bangladesh Institute of Health Science, Dhaka, Bangladesh; ${ }^{5}$ Assistant Professor, Department of Gastroenterology, Rajshahi Medical College, Rajshahi, Bangladesh; ${ }^{6}$ Associate Professor, Department of Public Health, North South University, Dhaka, Bangladesh

[Received on: 2 July 2018; Reviewed on: 12 July 2018; Accepted on: 1 August 2018; Published on: 1 January 2019]

\section{Abstract}

Background: Birth weight is the most important predictor of newborn health and survival and is associated with higher risk of infant and childhood mortality. Objective: The objective of this study was to assess the maternal and socio-demographic factors of low birth weight (LBW) newborns of mothers admitted at a teaching medical college hospital in Dhaka city of Bangladesh Methodology: This was a cross sectional study. Interview was taken by face to face interview and was focused to obtain the information about maternal weight at onset gestation, before delivery, educational, economical status of family, antenatal care visits, maternal exposure to hypertension and anaemia. Data had been collected from interview and medical records. Results: This study revealed from multivariate liner regression analysis. In this model, birth weight had been considered as continuous variable and results had depicted the relationship of different maternal factors with birth weight. This study suggests that there were several factors which lead to LBW babies. The study shows ANC visits ( $p$ value 0.05 ), number of parity ( $p$ value .02 ) and hypertension ( $p$ value 0.02 ) had significant negative effect of on birth weight. Mothers who had taken less ANC visits, more chance of having LBW.Hypertensive mothers were at risk of having low birth weight babies than normotensive mothers. Number of parity was also found as a significant factor. Primi mothers were more prone to LBW. Conclusion: This study suggests that less ANC visits, increase number of parity and hypertension have significant negative effect of on birth weight. [Journal of Current and Advance Medical Research $2019 ; 6(1): 47-52]$

Keywords: Maternal; Socio-demographic; Birth weight; Newborn

Correspondence: Dr. Sadia Afrin, MD Resident, Department of Physiology, Bangabandhu Sheikh Mujib Medical University, Dhaka, Bangladesh; Email: sadia838536@ gmail.com; Cell no: +8801710838536

Cite this article as: Afrin S, Rahman A, Ahammed A, Afrin S, Sarker MK, Hossain A. Maternal and Socio-Demographic Factors Associated with Birth Weight of Newborns Delivered at a Teaching Hospital of Dhaka City. J Curr Adv Med Res 2019;6(1):47-52 Funding: This study has been performed without any funding from outside else.

Conflict of Interest: There was no conflict of interest to any of the authors.

Contributions to authors: Afrin S, Rahman A, Ahammed A, involved in protocol preparation, data collection \& statistical analysis were by Afrin S; Ahammed A, Afrin S, Sarker MK, Hossain A had involved in manuscript writing \& revision of the manuscript Copyright: (02019. Afrin et al. Published by Journal of Current and Advance Medical Research. This article is published under the Creative Commons CC BY-NC License (https://creativecommons.org/licenses/by-nc/4.0/). This license permits use, distribution and reproduction in any medium, provided the original work is properly cited, and is not used for commercial purposes. 


\section{Introduction}

Birth weight is the weight of the body of a baby at its birth $^{1}$. It is the most important predictor of newborn health and survival and is associated with higher risk of infant and childhood mortality. Low birth weight (LBW) is defined as a birth weight of a live born infant of less than $2,500 \mathrm{~g}$ (5 pounds 8 ounces) regardless of gestational age ${ }^{2}$. LBW is a serious problem in our country. Day by day it is becoming more serious. It is closely associated with fetal and perinatal mortality and Morbidity, inhibited growth and cognitive development, and chronic diseases later in life. At the population level, the proportion of babies with a LBW is an indicator of a multifaceted public-health problem that includes long-term maternal malnutrition, ill health, hard work and poor health care in pregnancy ${ }^{3}$.Low birth weight is influenced by many socio-economic factors like habitat, urban or rural, education, birth order, substance abuse by mother, religion and caste, age of mother, nutritional status, body mass index, hemoglobin level, quality of ante-natal care received (ANC) and spacing of pregnancies. Low birth weight babies pose challenge to the families and neonatal mortality and also towards mental, physical and development challenges in pediatric population ${ }^{4}$.

Medical risk factors for LBW before pregnancy are chronic conditions like hypertension, renal insufficiency, cardio-respiratory, autoimmune, endocrine or infectious disorders. The risk factors for LBW during pregnancy are hypertensive disorders, diabetes, malnutrition, bleeding, anemia, infection, placental or fetal anomalies and multiple pregnancies. Maternal weight gain is a very influencing criteria for infant birth ${ }^{1}$. It is generally accepted that women should not attempt to lose weight during pregnancy. Therefore, interventions during pregnancy aim to limit weight gain throughout gestation, a factor, which has strong correlations with long-term health risks associated with obesity for both the mother and the child $^{6}$. Women who don't gain enough weight gain during pregnancy are more likely a low-birth weight baby than women who gain the right amount of weight ${ }^{7}$.

The cohort of LBW (birth weight $<2.5 \mathrm{~kg}$ ) babies is likely to reflect two effects, namely a short gestational age (preterm births) and small for gestational age (SGA). Small for gestational age usually results from intra-uterine growth restriction (IUGR). However, if the mother is small, it may be normal for her to have a small fetus. In the current study gestational age is included as an explanatory variable, therefore, the study is focused on the identification of risk factors for the complementary effect which is $\mathrm{SGA}^{8}$. Because of the tremendous advances in care of sick and premature babies, more and more babies are surviving despite being born early and being born very small. However, prevention of preterm births is one of the best ways to prevent babies born with low birth weight. Prenatal care is a key factor in preventing preterm births and low birth weight babies. At prenatal visits, the health of both mother and fetus can be checked. Because maternal nutrition and weight gain are linked with fetal weight gain and birth weight, eating a healthy diet and gaining the proper amount of weight in pregnancy are essential ${ }^{9}$.

\section{Methodology}

The study was carried out at Bangladesh Medical College and Hospital at Dhanmondi in Dhaka city of Bangladesh from July 2010 to June 2011 for a period of one (01) year. The study was designed as a cross sectional study. Interview was taken with sample size of 132 by face to face interview. Mothers who gave live birth in Bangladesh Medical Hospital, gave consent willingly for the interview, had the records of weight from beginning of pregnancy up to delivery, had no complication like gestational diabetes, multiple pregnancy, antepartum haemorrhage, STI, premature rupture of membrane, had taken at least 2 ante-natal checkup (ANC) visits $\&$ taken iron -vitamin supplementation and tetanus toxoid (TT) doses were included in the study. Mothers who refused to give consent and were not able to give interview due to sickness were excluded from the study. Birth Weight of newborns considered as low if birth weight was less than $2500 \mathrm{gm}$ and normal if birth weight was $\geq 2500 \mathrm{gm}$. Socio-demographic factors were age, education level, occupation, family income, residence. Maternal factors were mothers weight at onset of gestation, weight before delivery, height, weight gain, parity, hypertension, anaemia. Behavioral factors were duration of sleep, tea/coffee consumption/per day, number of ANC visits. Study sample had been selected purposively to interview the mother population who gave live birth at least 22 weeks of gestation. This study provide quantitative data taken by development of questionnaire and medical documents. A semi-structured questionnaire had been used as a data collection tool in the study. Pre-tasting of the check list had been done to ensure its adequacy, appropriateness and quality. Data were collected in every working day. Data were analyzed using Epi-Info version 6.2 (Centers for Disease Control and Prevention, Atlanta, GA) and validated by logical and range checks with SPSS version 16.0. Stepwise multiple logistic regression was then 
applied for the identification of significant risk factors using SPSS version 16.0. Approval from North South University, Bangladesh Medical Hospital were taken prior to commencement of the study. The study was reviewed and approved by the Scientific Advisory Committee (SAC) and Institutional Ethical Committee. Informed consent was obtained from all patient before including them into study.

\section{Result}

The data comprised 132 women who were at least 22 weeks of gestation and give a live birth. To find out maternal and socio-demographic factors associated with birth weight, we had shown here some figures.

\section{Birth Weight corresponds to weight at onset and before delivery}

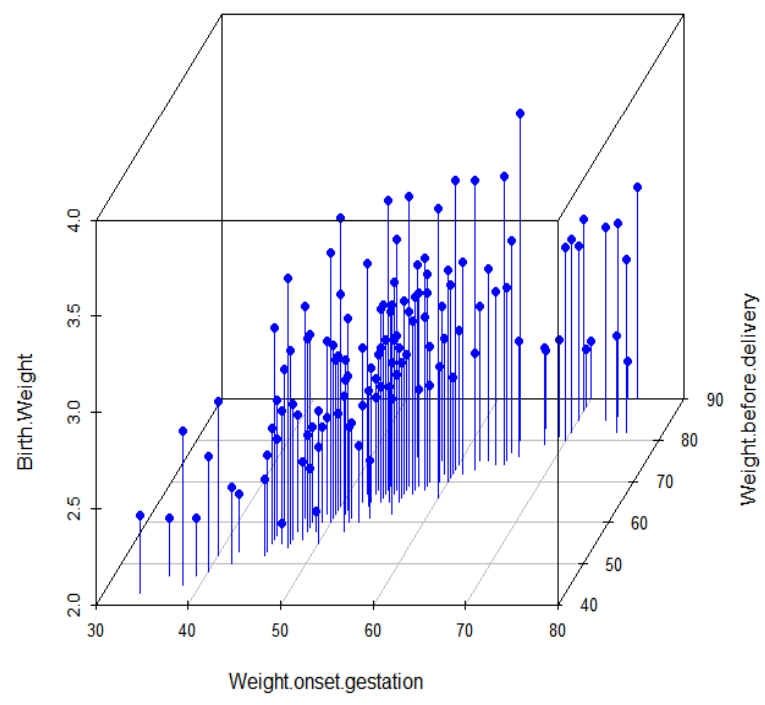

Figure I: shows the relationship between weight at onset gestation and before delivery with birth weight.

Here, Figure I, shows the relationship between weight at onset gestation and before delivery with birth weight. It appears that when weight at onset gestation is low, birth weight was also low.

With the increase of maternal weight at onset gestation, birth weight increases. But when it becomes more, birth weight falls. This was same for gestational weight before delivery too.

Figure II, shows how birth weight corresponds to age and weight at onset gestation. When maternal age was low $(<20)$, birth weight was low. With the increase of age and weight at onset gestation, birth weight improves. But when age was more (near about 40) birth weight decreases.

\section{Birth Weight corresponds to Age and weight at onset gestation}

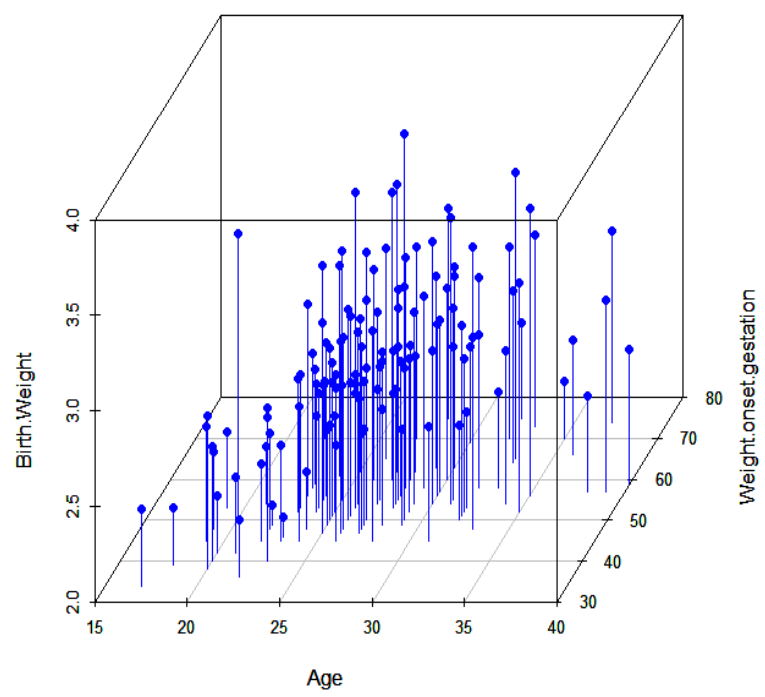

Figure II: shows how birth weight corresponds to age and weight at onset gestation

The study shows that birth weight was more in case of mothers with higher secondary and graduation than the mothers whose education level primary and secondary. With increase of education level birth weight improves. Birth weight was proportionate to income and residence which reflects that with increasing income level birth weight increases. And in case of residence those mothers live in urban area, their birth weight more than who live in rural area.

When maternal age was low $(<20)$, birth weight was low. With the increase of age and weight at onset gestation, birth weight improves. But when age was more (near about 40) birth weight decreases.

Figure III, shows boxplot of hypertension and anaemia. Here we can see birth weight was better in normotensive mothers than hypertensive mother. In case of anaemic and non-anaemic mothers, there was no such differences seen on birth weight. Figure IV, boxplot of delivery method and ANC visit. Delivery method had no significant effects on birth weight. In case of ANC visits, it shows that mothers who had taken 4 or more than 4 visits their birth weight were more than who did take less visits. In this study regarding taking tea and sleep and in both sectors they cannot be considered as influencing factors of birth weight. 

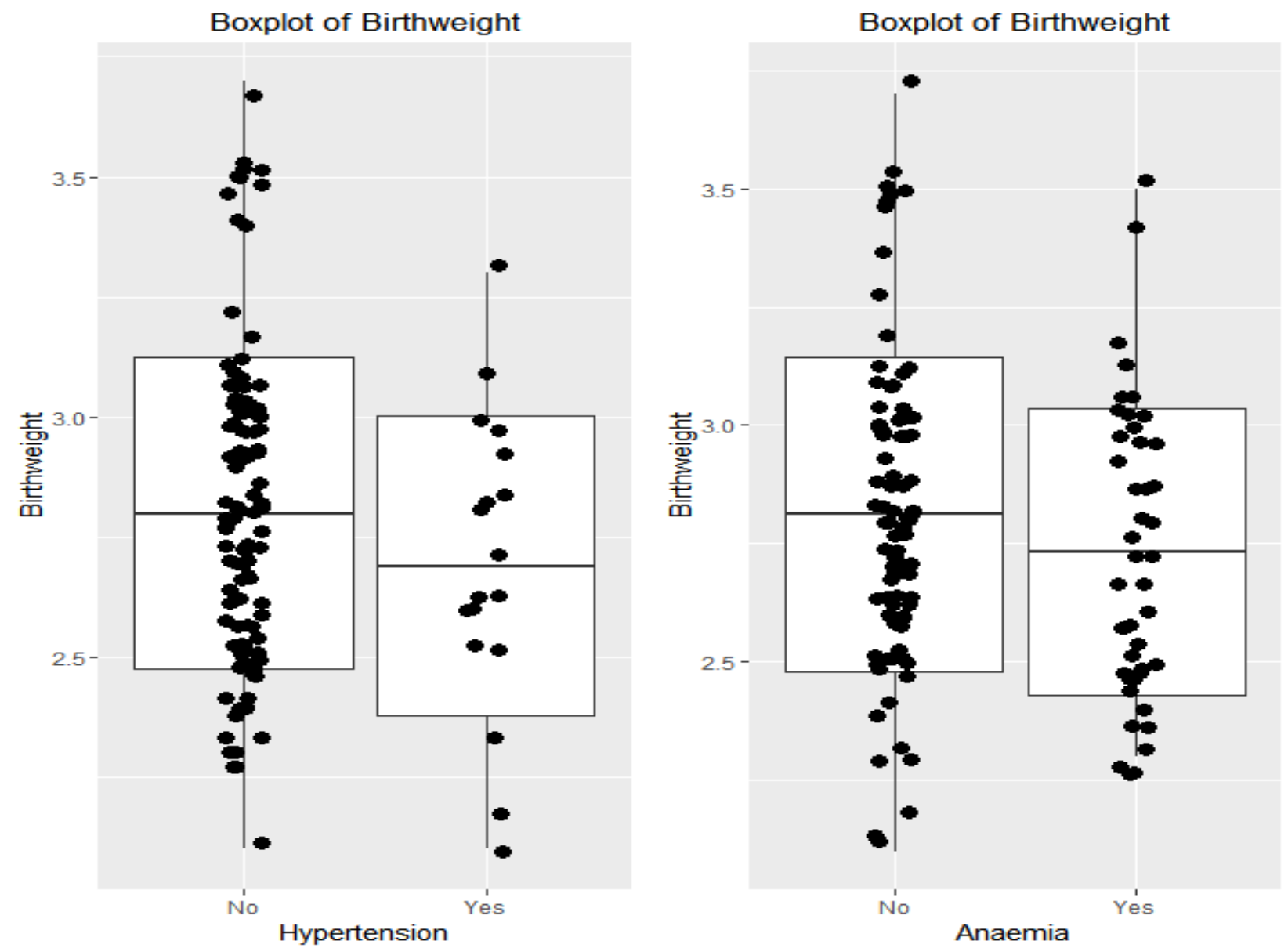

Figure III: shows boxplot of hypertension and anaemia

Boxplot of Birthweight

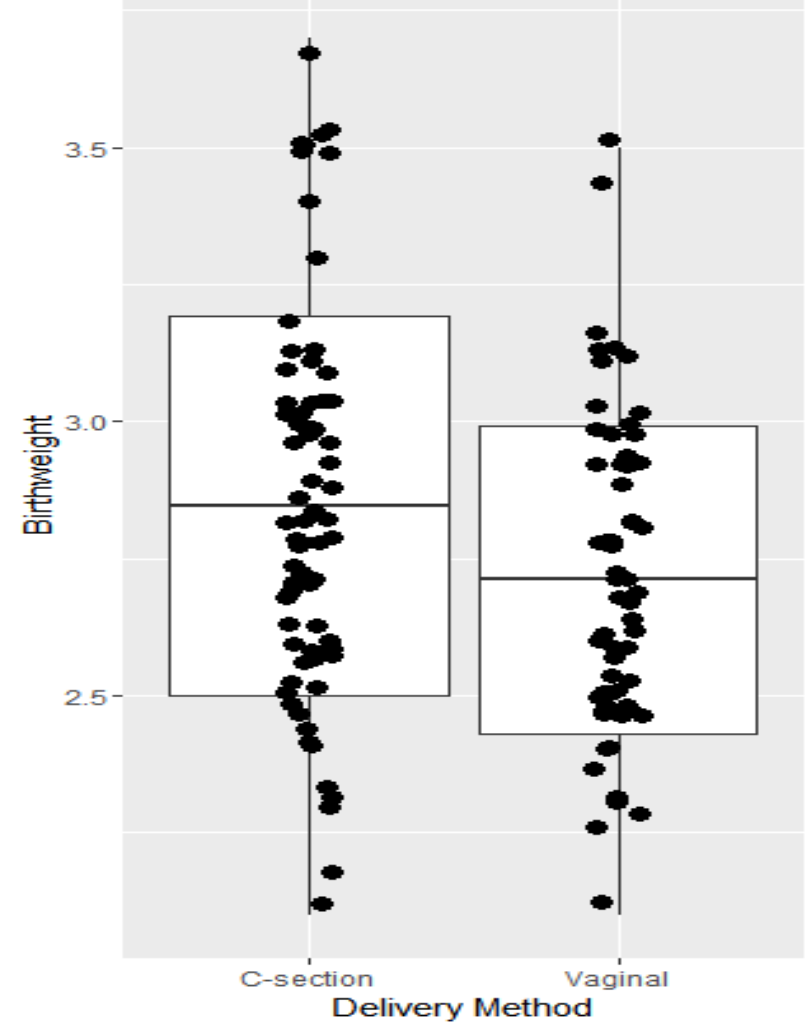

Boxplot of Birthweight

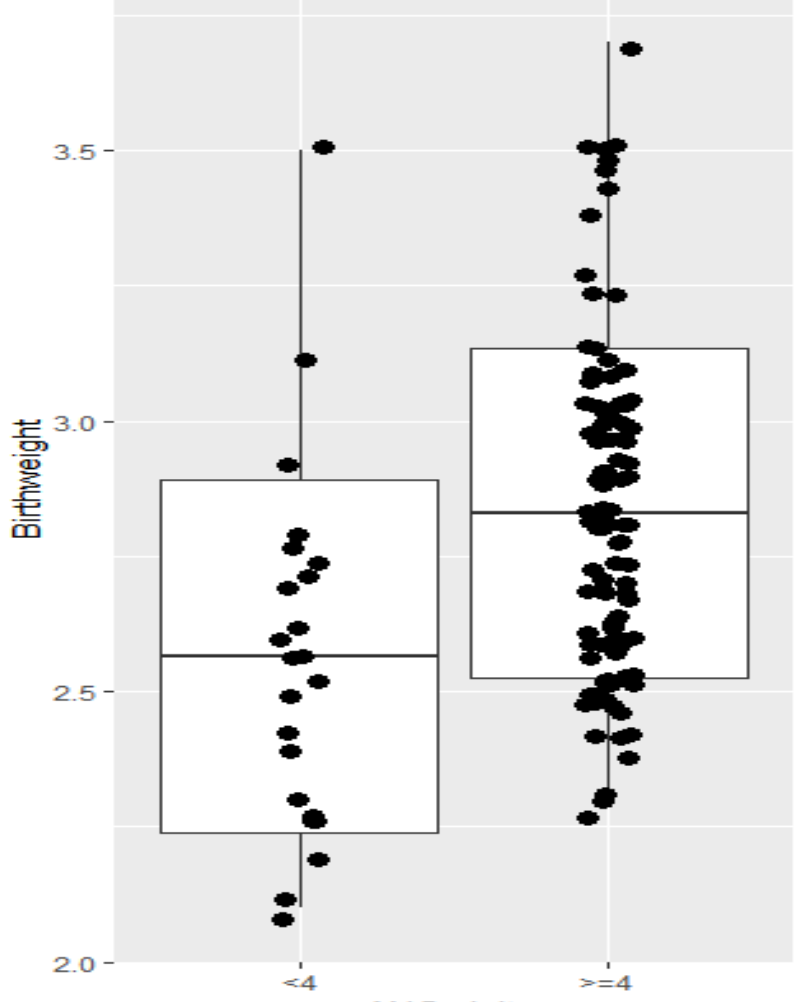

ANC visits

Figure IV: boxplot of delivery method and ANC visit 
Table 1: Adjusted Analysis by Multivariate Linear Regression Model

\begin{tabular}{|c|c|c|c|c|c|}
\hline Variables & Reference & Estimate & Std. Error & t value & P value \\
\hline Age & & 0.007601 & 0.009033 & 0.842 & 0.4018 \\
\hline $\begin{array}{l}\text { Education } \\
\text { Graduation } \\
\text { Higher Sec. } \\
\text { Secondary }\end{array}$ & Primary & $\begin{array}{l}0.091133 \\
0.079635 \\
-0.03077\end{array}$ & $\begin{array}{l}0.145024 \\
0.129531 \\
0.098559\end{array}$ & $\begin{array}{r}0.628 \\
0.615 \\
-0.305\end{array}$ & $\begin{array}{l}0.53100 \\
0.5399 \\
0.7608\end{array}$ \\
\hline $\begin{array}{l}\text { Occupation } \\
\text { Working }\end{array}$ & House wife & 0.032962 & 0.076956 & 0.428 & 0.6692 \\
\hline $\begin{array}{l}\text { Income level } \\
15000-30000 \\
>30000\end{array}$ & $<15000$ & $\begin{array}{l}0.052834 \\
0.084922\end{array}$ & $\begin{array}{l}0.100276 \\
0.089725\end{array}$ & $\begin{array}{l}0.589 \\
0.847\end{array}$ & $\begin{array}{l}0.5571 \\
0.3988\end{array}$ \\
\hline $\begin{array}{l}\text { Residence } \\
\text { Urban } \\
\text { N. Parity (Multi parity) }\end{array}$ & $\begin{array}{l}\text { Rural } \\
\text { Primi parity }\end{array}$ & $\begin{array}{l}0.018033 \\
0.265892\end{array}$ & $\begin{array}{l}0.072479 \\
0.117549\end{array}$ & $\begin{array}{l}0.249 \\
2.262\end{array}$ & $\begin{array}{l}0.8040 \\
\mathbf{0 . 0 2 5 6}\end{array}$ \\
\hline Weight gain & & -0.0086 & 0.0116 & -0.745 & 0.4580 \\
\hline $\begin{array}{l}\text { ANC visits }(\geq 4) \\
\text { Anaemia (Yes) } \\
\text { HTN(Yes) } \\
\text { Sleep } \\
>=6\end{array}$ & $\begin{array}{l}<4 \\
\text { No } \\
\text { No }\end{array}$ & $\begin{array}{c}0.120851 \\
-0.024522 \\
-0.19211 \\
0.032463\end{array}$ & $\begin{array}{l}0.080102 \\
0.059166 \\
0.085412 \\
0.065453\end{array}$ & $\begin{array}{r}1.509 \\
-0.414 \\
-2.332 \\
0.249\end{array}$ & $\begin{array}{l}\mathbf{0 . 0 5 4 2} \\
0.6793 \\
\mathbf{0 . 0 2 1 5} \\
0.8040\end{array}$ \\
\hline $\begin{array}{l}\text { N. cup .tea } \\
\text { No } \\
1-2\end{array}$ & $3-4$ & $\begin{array}{l}0.106271 \\
0.037775\end{array}$ & $\begin{array}{l}0.087871 \\
0.083022\end{array}$ & $\begin{array}{l}1.209 \\
0.455\end{array}$ & $\begin{array}{l}0.2290 \\
0.6500\end{array}$ \\
\hline $\begin{array}{l}\text { Delivery } \\
\text { (Vaginal) }\end{array}$ & $\mathrm{C} / \mathrm{S}$ & -0.0854 & 0.056 & -1.510 & 0.337 \\
\hline
\end{tabular}

It had been fitted multivariate linear regression model where birth weight was considered as continuous variable and results were given in Table 1. This table describes the relationship of different maternal factors with birth weight. The table shows ANC visits ( $\mathrm{p}$ value 0.05 ) and number of parity ( $\mathrm{p}$ value .02) as significant factors. And significant negative effect of hypertension on birth weight $(\mathrm{p}$ value 0.02) that means mothers who had hypertension had higher chance of giving low birth weight baby.

\section{Discussion}

The present study, shows that number of ANC visits as significant factor. In comparison with literature review "Maternal Risk Factors Associated with Term Low Birth Neonates: A Matched-Pair Case Control Study" in NDMVPS medical college Mahrashtra $^{10}$ India revealed inadequate ANC associated with low birth weight which is similar to this study. Compared to another study conducted by
Deshmukh et al $^{11}$ revealed that primi parity are significantly risk factor for LBW. This present study also found number of parity as a significant factor \& primi parity are prone to have low birth weight baby.

In this study there is negative significant effect of hypertension on birth weight. Hypertensive mothers have higher chance of giving LBW which is similar to the study by Odell $\mathrm{CD}^{12}$ where hypertension is a strongly significant risk factor for LBW. Matin A et $\mathrm{al}^{13}$ also found the same contributing factor on LBW. The results showed high level of association between maternal educations, economic status and anaemia with low birth weight.The study found no significant association between anaemia and birth weight. Kramer's ${ }^{4}$ Meta-analysis and other studies conducted in developing countries have identified maternal weight $(<45 \mathrm{~kg})$, maternal height $(<145$ $\mathrm{cm}$ ) as potential risk factors for LBW babies. Low socio-economic status and low educational studies lead to low social consciousness leading to the increased risk of Low birth weight babies. 
The present study found that age, education, family income, weight at onset of gestation and before delivery as influencing factors for LBW. No significant association between height and birth weight is found. There are some limitations in this study as it was done in one hospital so it cannot be true representative of the whole country scenario. As there are several factors interacting in this phenomenon so it is not feasible to single out any particular factor affecting low birth weight. Hence, it is the need of the hour to strengthen the existing maternal services at the community level to prevent and reduce $\mathrm{LBW}$.

\section{Conclusion}

This study suggests that ANC visits, number of parity and hypertension have significant negative effect of on birth weight. Thus the findings of this study emphasizes the need of utilization of antenatal care, prevention and proper management of disease like hypertension will contribute to reduce low birth weight in Bangladesh.

\section{Reference}

1. Rasmussen KM, Yaktine AL, editors. Weight gain during pregnancy: reexamining the guidelines. Washington, DC: The National Academies Press; 2009.

2. P07 - Disorders related to short gestation and low birth weight in ICD-10.

3. Stevens-Simon C, Orleans M. Low-birthweight prevention programs: The enigma of failure. Birth. 1999 Sep;26(3):184-91
4. Kramer MS. Determinants of low birth weight: methodological assessment and meta-analysis. Bull World Health Organ 1987; 65: 663-737

5. Col GS, Capt RC, Maj KS. Maternal factors for low birth weight babies. Medical Journal Armed Forces India. 2009; 65(1):10-2

6. Maternal weight gain during pregnancy and neonatal birth weight: a literature review. Santo Monte, Oriana Valenti, Elsa Giorgio, Eliana Renda, Entela Hyseni, Marianna, Faraci , Roberta De Domenico, Fosca A. F. Di Prima J Prenat Med. Monte S, Valenti O, Giorgio E, Renda E, Hyseni E, Faraci M, De Domenico R, Di Prima FA. Maternal weight gain during pregnancy and neonatal birth weight: a review of the literature. Journal of prenatal medicine. 2011 Apr;5(2):27.

7. Low birth weight. March of dimes. Available from: http://www.marchofdimes.org/baby/low-birthweight.aspx.

8. UNICEF: Low Birth Weight, Country Regional and Global estimates.

http://www.unicef.org/publications/index_24840.htm1, website accessed July 13, 2005.

9. Low Birthweight-Lucile Packard Children's Hospital Stanford. Available from: http://www.stanfordchildrens.org/en/topic/default?id=low-

birthweight-90-P02382

10. Nagargoje MM, Chaudhary SS, Deshmukh JS, Gupta SC, Misra SK. A Case Control Study of Risk Factors for Low Birth Weight in Nagpur City of Maharashtra. Indian Journal of Community Health. 2011;23(1):4-7

11. Deshmukh JS, Motghare DD, Zodpey SP, Wadhva SK. Low birth weight and associated maternal factors in an urban area. Indian Pediatr 1998;35:33-36

12. Eapen DJ. A qualitative description of pregnancy related social support experiences of low-income mothers with low birth weight babies (Doctoral dissertation, University of Kansas).

13. Matin A, Azimul SK, Matiur AK, Shamianaz S, Shabnam

$\mathrm{JH}$, Islam T. Maternal socioeconomic and nutritional determinants of low birth weight in urban area of Bangladesh. Journal of Dhaka Medical College. 2008;17(2):83-7. 